\title{
Grandeza de una alma: Amparo Gaos Schmidt (Málaga, España, 11 de agosto de 1934- Ciudad de México, México, 11 de julio de 2020)
}

\author{
Bulmaro Enrique ReYEs CORIA \\ https://orcid.org/0000-0002-2494-2495 \\ Universidad Nacional Autónoma de México, México, \\ omfann2@gmail.com
}

Palabras ClaVe: Amparo Gaos, Cicerón, filología, amistad

KEYWORDS: Amparo Gaos, Cicero, Philology, Friendship

RECIBIDO: 30/09/2020 • ACEPTADO: 07/10/2020 • VERSIÓN FINAL: 12/10/2020

Era viernes de terror ledo, a las seis de la tarde, en la Facultad de Filosofía y Letras. Acompasados tacones la transportaban, y ése era su involuntario modo como se daba a conocer. Era ella, Amparo Gaos, acompañada por su gigantesco amigo Rubén, llegando a examinar mi trémula tesis doctoral. Hace casi cuarenta años, y aún recuerdo aquel rostro severamente hermoso, superior a cualquiera, y su traje sastre azul marino que, virtuosamente pulcro, cubría su alma rematada con peinado eterno a la Margaret Thatcher. No miento y no hago tropos: con toda claridad vi cómo, ante semejantes jueces, Marco Tulio Cicerón, Quintiliano y su otra docena de seguidores me abandonaban con mi fardo de invención retórica; con toda claridad vi cómo, tras ellos, los 644 folios de mi esperanza académica se precipitaban por la ventana de aquella elevada aula del posgrado, y con toda claridad vi cómo volvían en fila a su encuadernación primera, pero vacíos de palabras. ¡Era, a no dudar, el principio del fin de mi carrera!

- Querido amigo Bulmaro - como enviada del cielo resonó en mis oídos la voz más cálida que entre vocales y consonantes clásicas había yo escuchado en la vida; provocó, de hecho, que durante su inquisición mi escritura volviera a sentarse en sus renglones, cuando dijo-: te felicito por tan ingente trabajo.

Yo sabía de cierto lo que ingente, en primera instancia, significaba para una latinista de la talla de la doctora Gaos: tan sólo de tamaño inmoderado; of immoderate size, según el diccionario que ella normalmente usaba. Paso en silencio, por causa de la retórica, las poquísimas bondades con que suavi- 
zaba la ignominia que habrían de causar sus objeciones a mis letras fugitivas. Pero recuerdo que la ignominia nunca llegó, porque el presidente del jurado, su gigantesco amigo, pronunció no sé qué inaudible conjuro, tan mágico que la maestra reconoció que en verdad aquello era ingente, pues a leguas era notorio su enorme tamaño.

Pocos días después, como si hubiera estado cazándome, me llamó desde la puerta de su cubículo del Centro de Estudios Clásicos, y con la misma melodía:

-Querido amigo Bulmaro, ¿quieres pasar a mi oficina unos minutos por favor?

Ahí adentro, sobre su límpido escritorio, asaz femíneo por cierto, discutían espantosamente, en un rincón, Ernout-Thomas, Lewis-Short, Jules Lebreton, Hammond-Scullard y Orellius-Baiterius, y, en otro, Herbert Weir Smyth, en presencia del mismísimo Marco Tulio Cicerón, mejor amigo de Amparo. Creo que contendían por el simple vocablo numerus, y, como ése para mí no tenía dificultad ninguna, osé meter paz entre tamaños dueños de la filología. No lo hubiera hecho, pues, al parecer, lo que aquéllos querían era finiquitar el asunto que, casi luctuoso para mis letras, el presidente había dejado cesante aquel viernes de mi salvación providencial. Como haya sido, me enfrenté a semejantes ex ruditos, que reñían por la traducción, que disputaban la perspectiva, que se resistían a la interpretación, y que incluso calumniaban la redacción española. Pero cuando estaba yo a punto de perecer en las garras de ellos, la doctora Gaos les dio la espalda para protegerme de sus dardos.

Con indecible dulzura, como para aliviar las heridas ya causadas por aquella gentuza, pero no sin mostrarme las objeciones que de mi trabajo hubo de callar en el examen, expresó el gusto que sentía por tenerme como su colega, de modo especial por haberme entregado yo, como ella, al estudio de Marco Tulio Cicerón, y mejor todavía, como ella, a la retórica de aquel abogado romano, de quien ella había ya estudiado, en particular, los discursos Pro Caelio e In Catilinam, los diálogos De amicitia y De oratore, la más grande reflexión ciceroniana, que habría de tribuirle grandes frutos, y, en general, pero no con menor profundidad, la entera obra filosófica y epistolar del mismo Tulio, como ella misma lo evidenciaba en sus conversaciones cotidianas, y siempre seguirá evidenciándolo en su libro Cicerón y la elocuencia.

Exhibió, entonces, la grandeza de su alma, no solamente con las palabras, sino poniendo en mis manos, a manera de herencia, algo para mí inasequible: unas urnitas de Latoyo donde se ocultaban las armas de los que me querían arruinado:

- Era la primera el Onomasticon Tullianum continens M.Tullii Ciceronis Vitam, Historiam litterariam, Indicem geographicum et historicum, Indicem legum et formularum, Indicem Graeco-Latinum, Fastos consula- 
res (1838) de los veteranos Ioannes Casparus Orellius y Ioannes Georgius Baiterus.

- La segunda, los Études sur la langue et la grammaire de Cicéron (1901) del irreductible Jules Lebreton.

- La tercera, la Greek grammar (1920) del invicto Herbert Weir Smyth.

- La cuarta, la Syntaxe latine (1951) de los doquier empáticos Alfred Ernout y François Thomas.

- Inexplicablemente, Charlton Thomas Lewis y Charles Short salieron huyendo con su Latin Dictionary, exigiendo cada quien su parte.

Y éstas fueron armas sin las cuales mis afanes habrían sido aun más frágiles. Con hincapié lo digo: la doctora Gaos, en el Instituto de Investigaciones Filológicas, fue la estudiosa de la teoría retórica de Marco Tulio Cicerón, y yo me hallaba ahí metido sin siquiera haber sido invitado. Bueno, bueno, Amparo me hizo saber que nadie era dueño de la cultura grecolatina. Que cualquiera, con absoluta libertad, podía adueñarse de cualquier filón suyo, grande o pequeño, y cuánto mejor si crecía el número de esos pretendientes. Que nadie era quien para impedirlo. Que debíamos, al contrario, empeñarnos en generar vocaciones para tales estudios, pues el conocimiento de la cultura grecolatina era de crucial momento en México, como en el mundo entero. Digo esto con hincapié, por ser ésa una de las grandes virtudes de Amparo: la generosidad. De hecho, repito, era ella la que en el Centro de Estudios Clásicos trabajaba la retórica ciceroniana (nada más y nada menos que, en ese entonces, el $D e$ oratore); era aquél su proyecto, acaso de vida, pero no se opuso a que yo me sumara a él. Años después (en Aprender a investigar) haría público que la investigación puede volverse frustrante y tediosa si uno mismo no elige el tema que le interesa. Y en prueba de semejante alma grande, recibí allí mismo, gratuitamente, herencia inalienable, aquellas urnas latoyanas, sin duda, para que con menores dificultades me dedicara al tema de la retórica ciceroniana en que ella hacía años era la experta. A pocos meses de esta experiencia, otra vez con el canto que yo amaba, escuché:

-Querido amigo Bulmaro, ¿puedes pasar un momento por favor? Quiero contarte algo. Mira: ya voy muy adelantada en la traducción de las Noches Áticas de Aulo Gelio. Estoy muy entusiasmada, porque, como bien sabes, esta obra no está al alcance de los estudiantes. Nuestros maestros apenas si nos decían que se trataba de una compilación extravagante y desordenada, aunque llena de noticias abstrusas y eruditas, sin siquiera hacernos saber que, al final del prefacio, Gelio mismo proporcionaba el sumario de cada uno de los veinte libros de que consta la obra.

En cambio, la doctora, obediente a su afecto por la docencia, emprendió la traducción de esos libros, la cual publicó en cuatro gruesos volúmenes, y fue más allá al añadir al primero, como al De oratore, una introducción general 
y, para cada uno de los veinte libros, cuantas notas consideró necesarias para la enseñanza-aprendizaje de la gramática latina, o para la comprensión o aprehensión de la antigüedad clásica, así como sendos índices onomásticos, que al final fundiría en sus Índices de las Noches Áticas de Aulo Gelio. Con éstos, debo testificar, ella inició una colección ahijada de su Bibliotheca Scriptorum Graecorum et Romanorum Mexicana, llamada Supplementum. Y una vez, durante los años de este su Aulo Gelio, como si fuera la voz de mi conciencia, me llamó:

- Querido amigo Bulmaro, quiero pedirte un favor.

Con ese exordio deprecatorio vi venir la oportunidad para abonar algo a mi gran deuda de nuestra amistad. Llanamente me pidió que leyera lo que yo nunca había imaginado de ella: un libro de nombre Aprender a investigar. Para mis más profundos adentros me dije "Pues ahora es cuando", dado que en esa materia no me sentía inferior a nadie. Con devoción verdadera leí las 147 cuartillas de que constaba. Las cuales, bajo mis numerosas anotaciones inútiles, me hicieron ver, aparte de un camino de investigación, principalmente la esencia de la autora: por encima de todo, era docente. Amparo era la maestra en lo que hacía y en lo que enseñaba, y aun enseñaba cómo enseñar. Tan manirrota era que ni siquiera escondió, egoístamente para sí, el método de su trabajo; al contrario, lo compartió con cuantos quisieran aprenderlo. Su método se halla, aún, al alcance de todos los que lo necesiten, o de los profesores que tengan voluntad de enseñarlo. No dudo que al componerlo hubiera pensado en mí, así fuera un instante, pues alguna vez ya me había advertido que yo comenzaba todo in medias res. Lo que eso significara había que reflexionarlo, pues ahí estaba la potencial enmienda. En tal caso, no era su intención pedir favor, sino hacerlo: me dio clases de investigación sin que yo me diera cuenta. Sí que leyó y conoció y practicó la retórica ciceroniana de su De oratore.

- Querido amigo Bulmaro - con el mismo aire de entusiasmo, acercándose una vez más con su no reciente dificultad al umbral del Centro de Estudios Clásicos del Instituto de Investigaciones Filológicas de la Universidad Nacional Autónoma de México, para la cual, contando desde su Antología de la poesía latina, empeñó su vida por más de 60 años en el estudio y enseñanza de la antigüedad clásica grecolatina, repito, al llegar así, en plena batalla contra la excesiva y añeja violencia que diezmaba con dolor físico y moral su dactilografía, pero exhalando un espíritu de satisfacción tan grande como nunca antes había yo mirado, me anunció-: ¡iiiYáaa terminéee Suetóoonio!!!! - como si alguna vez lo hubiera considerado imposible, y añadió-: Me gustaría que tú lo leyeras antes de entregarlo.

Me contó, esa mañana, cuántas cosas había aprendido: qué es la historia, qué no es la historia; los autores de anales; lo que escribieron y cómo lo escribieron. Con envidiable precipitación — todo lo sabía de memoria - hablaba 
de Nepote, de Floro, de Tácito, como si éstos la hubieran autorizado a pergeñar su propia teoría acerca de la historia y la historiografía. Todo me lo contaba con el detalle sólo posible en quien domina la materia de que se habla. Me enseñó, por decir lo menos, que Julio César fue quien dividió el pergamino en páginas que, ya no en rollo, diariamente enviaba al senado para que en Roma se difundieran sus hazañas de las Galias. Era por excelencia la maestra de la cultura latina. Y, sin embargo, dejé pasar irremediablemente la oportunidad de escuchar las cosas que no dejó en papel.

Por todo ello y más que la pluma no supo escribir, aunque de otro modo que su respetable y hermosa familia continuada por Alia, Amparo, Ernesto y Rubén; sin embargo, no con pena menor, no sólo lamento la ausencia de aquella voz de energía suave, que entonaba docencia, que infundía pasión por el estudio de las letras clásicas, tan clara como las mejores entre las letras; también habré de añorar las huellas sonoras que anunciaban su llegada.

-Y quizá no miento, querida amiga Amparo, si afirmo que esta ausencia de ti nos lastima a tus amigos, a todos, del Instituto de Investigaciones Filológicas de la Universidad Nacional Autónoma de México, exactamente como lo dice ahora para ti tu amigo Marco Tulio Cicerón:

Nam si id dolemus, quod te iam frui nobis non licet, nostrum est id malum; quod modice feramus, ne id non ad amicitiam sed ad domesticam utilitatem referre videamur: sin tamquam tibi ipsi acerbitatis aliquid acciderit angimur, summam tui felicitatem non satis grato animo interpretamur.

"Pues si nos dolemos de que ya no nos es lícito disfrutarte, nuestro es este mal, el cual habremos de llevar con moderación, para que no parezca que no lo referimos a la amistad, sino a la utilidad doméstica; en cambio, si nos angustiamos como si te hubiera acaecido algo de amargura, interpretamos la suma felicidad de ti con ánimo no suficientemente agradecido".

Por mi parte, con sinícesis enniana, te aseguro esto:

Quia Mexico operam dabas, te pax Mexici reservabit, quam si quis quandoc conturbaret multi rationes pro te habebunt.

Tu amigo Bulmaro Reyes Coria

$$
* * *
$$

Bulmaro EnRiQue Reyes Coria es doctor en Letras (Clásicas) por la Universidad Nacional Autónoma de México, en cuyo Instituto de Investigaciones Filológicas es 
investigador titular de tiempo completo, y en cuya Facultad de Filosofía y Letras enseña latín. Estudia la obra retórica de M. T. Cicerón, y ha dedicado tiempo a Marcial, a Marciano Capela; a latines del Renacimiento europeo (Borromeo, Molano) y del dieciochesco mexicano (Fernández del Rincón). De Cicerón ha publicado, con introducciones, el discurso por las Provincias consulares, las tres primeras Filípicas y toda la obra retórica, excepto Acerca del orador, aunque incluida la Retórica a Herenio; además artículos y librillos de género símil. Su más reciente publicación es De historia ss. imaginum et picturarum auctore Joanne Molano, con nota editorial, edición del texto latino y traducción al español. 